\title{
Predicting Pyrolysis Products of PE, PP, and PET Using NRTL Activity Coefficient Model
}

\author{
Seyed Mousa FakhrHoseini and Majid Dastanian \\ Department of Chemical Engineering, Omidiyeh Branch, Islamic Azad University, Omidiyeh, Khuzestan 6373193719, Iran \\ Correspondence should be addressed to Seyed Mousa FakhrHoseini; s.m.fakhrhoseini@iauo.ac.ir
}

Received 4 May 2013; Revised 6 August 2013; Accepted 7 August 2013

Academic Editor: Diego Sampedro

Copyright ( 2013 S. M. FakhrHoseini and M. Dastanian. This is an open access article distributed under the Creative Commons Attribution License, which permits unrestricted use, distribution, and reproduction in any medium, provided the original work is properly cited.

\begin{abstract}
Using thermodynamic models is a desired method for predicting an equilibrium when occurring in a system. If a thermodynamic model can predict an equilibrium condition in a pyrolysis, for a new way will be open for scientists in predicting equilibrium in a reaction without need to kinetic models. In this work, low-density polyethylene, polypropylene, and polyethylene terephthalate were used instead of feed of pyrolysis process. The process was maintained at $500^{\circ} \mathrm{C}$ with 5 different temperature raising ratios $6,8,10,12$, and 14 . Then the process was modeled thermodynamically using NRTL activity coefficient model. Using this model, the binary interaction coefficients were investigated for the system of "char, oil, and gas." Results showed that polyethylene and polypropylene produced the maximum liquid product. Calculated RMSD objective function was 0.0157; that it is acceptable for this process.
\end{abstract}

\section{Introduction}

Using the activity coefficient models in a polymer degradation process via pyrolysis or thermolysis is unusual. These processes are usually evaluated by kinetic models. In pyrolysis reaction, three phases are produced, solid (char), liquid (tar), and gas. These three phases are immiscible, spontaneously. By considering a pyrolysis reaction as a process consisting of three solid, liquid, and gas phases, we can apply thermodynamic model on this system. The produced phases are immiscible, and they cannot be mixed together again. Based on the immiscible mixtures theory, we can assume a threephase mixture that is produced after changing a process variable. The process variable here is temperature.

Degradation of these large molecules depends on a number of different conditions including (but are not limited to) temperature, residence time, and the presence of catalysts [1]. The pyrolysis reaction can be carried out with or without the presence of catalyst. Accordingly, the reaction will be thermal and catalytic pyrolysis.

The main plastic wastes that are presented in the world are polyethylene, polypropylene, and polyethylene terephthalate.
Thus, the majority of scientists are trying to convert these three components [2-6]. Effect of various temperature conditions on pyrolysis products are shown in Table 1.

In this work, we try to convert PE, PP, and PET using pyrolysis process. Liquid product (tar) is one of the desirable products and could be used as a raw material for refining and producing petroleum light cuts. For this reason, in this research maximum liquid production is the main goal and process conditions are set to gain more liquid product.

\section{Material and Methods}

As it is mentioned in the previous section, various plastic wastes can be used as the raw material of pyrolysis. The plastic samples (LDPE, PP, and PET) were collected from Bandar Imam petrochemical complex. These samples were washed and dried in a vacuum oven in $50^{\circ} \mathrm{C}$, then samples were sliced in small pieces with approximately 2 millimeters dimension. The selected plastics convert to various products due to pyrolysis process.

Based on the previous works $[1,5,7-9]$, the pyrolysis pressure was considered at atmospheric pressure, and the 
TABLE 1: The selected plastic wastes and their different thermal decompositions and products during pyrolysis process [1].

\begin{tabular}{|c|c|c|c|}
\hline Resin & Mode of thermal decomposition & Low-temperature products & $\begin{array}{l}\text { High-temperature } \\
\text { products }\end{array}$ \\
\hline Polyethylene & $\begin{array}{l}\text { Random chain rupture (results in both } \\
\text { monomers and oligomers) }\end{array}$ & Waxes, paraffin oil, $\alpha$-olefins & Gases and light oils \\
\hline Polypropylene & Random chain rupture & Vaseline, olefins & Gases and light oils \\
\hline $\begin{array}{l}\text { Polyethylene } \\
\text { terephthalate }\end{array}$ & $\begin{array}{l}\text { b-Hydrogen transfer, rearrangement, } \\
\text { and decarboxylation }\end{array}$ & Benzoic acid and vinyl terephthalate & - \\
\hline
\end{tabular}

TABLE 2: Table of experiments used for pyrolysis of plastic wastes.

\begin{tabular}{lc}
\hline Plastic waste & $\begin{array}{c}\text { Temperature increasing } \\
\text { rate }\left({ }^{\circ} \mathrm{C} / \mathrm{min}\right)\end{array}$ \\
\hline LDPE & 6 \\
LDPE & 8 \\
LDPE & 10 \\
LDPE & 12 \\
LDPE & 14 \\
PET & 6 \\
PET & 8 \\
PET & 10 \\
PET & 12 \\
PET & 14 \\
PP & 6 \\
PP & 8 \\
PP & 10 \\
PP & 12 \\
PP & 14 \\
\hline
\end{tabular}

main variable parameter was temperature. The graphic representation of experimental setup is shown in Figure 1.

2.1. Pyrolysis Temperature. Based on the previous works, so many researchers considered a temperature between 400 and $600^{\circ} \mathrm{C}[1,5,7-9]$. Another variable parameter of pyrolysis is temperature increasing ratio. In this work pyrolysis temperature was considered at $500^{\circ} \mathrm{C}$, and various temperature increasing rates between 6 and $14^{\circ} \mathrm{C} / \mathrm{min}$ were considered. All samples were heated from lab temperature to $500^{\circ} \mathrm{C}$ based on heating rates that are shown in Table 2.

In order to prevent product oxidation, a nitrogen stream was carried out before heating period. The pyrolysis reactor was put in a Carbolite furnace that it can rise to $1200^{\circ} \mathrm{C}$ by different increasing rates. An exhaust stream was used for driving pyrolysis product to condenser. The condenser was cooling with silicon oil in shell side of the first exchanger and water in shell side of the second exchanger. After starting the reaction, pyrolysis product was entered into the tube side of heat exchanger. Then, pyrolysis liquid product was collected in a liquid sample bottle, and the solid product (char) remained in the reactor.

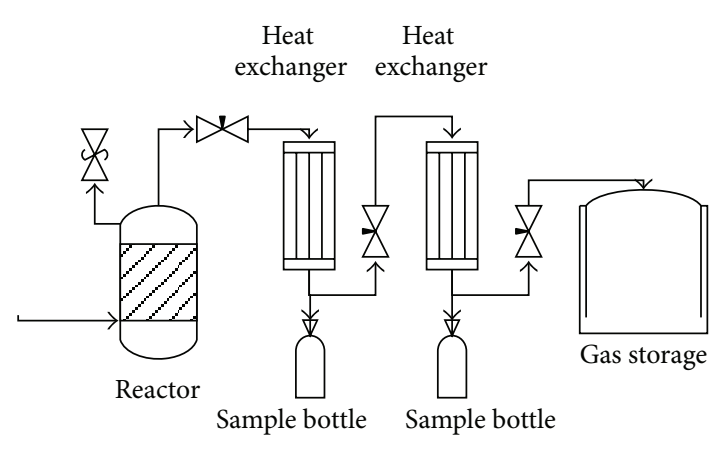

FIGURE 1: The schematic diagram of pyrolysis reactor.

2.2. Predicting Pyrolysis Product Using NRTL Activity Coefficient Model. In this work, we used NRTL activity coefficient model for predicting content of each produced weight (solidliquid-gas). This model could be used for nonideal systems by tuning the binary interaction coefficients. The NRTL model was presented by Renon and Prausnitz in 1969 [10].

Consider the following:

$$
\begin{aligned}
\operatorname{Ln} \gamma_{i}= & {\left[\frac{\sum_{j=1}^{c} x_{j} \tau_{j i} G_{j i}}{\sum_{k=1}^{c} x_{k} G_{k j}}\right] } \\
+ & \sum_{j=1}^{c}\left[\left(\frac{x_{j} G_{i j}}{\sum_{k=1}^{c} x_{k} G_{k j}}\right)\right. \\
& \left.\quad \times\left(\tau_{i j}-\left(\frac{\sum_{k=1}^{c} x_{k} \tau_{k j} G_{k j}}{\sum_{k=1}^{c} x_{k} G_{k j}}\right)\right)\right] .
\end{aligned}
$$

Consider:

$$
\begin{gathered}
G_{i j}=\exp \left(-\alpha_{i j} \tau_{i j}\right), \\
\tau_{i j}=a_{i j}+\frac{b_{i j}}{T} .
\end{gathered}
$$

In this equation, $a_{i j}$ and $b_{i j}$ are two binary interaction coefficients that are tunable. By using reaction temperature and mass fraction of each phase, these binary interaction parameters can be adjusted and used at similar condition. Based on the model description, we have:

$$
\tau_{i i}=0, \quad a_{i j} \neq a_{j i}, \quad b_{i j} \neq b_{j i},
$$

$\alpha_{i j}$ is nonrandomness parameter and $\alpha_{i j}=\alpha_{j i}$. This parameter is a value between 0.2 and 0.47 that is considered 
a constant value equal 0.3 in most papers. In this work we used $\alpha_{i j}=0.3$.

In order to obtain the binary interaction parameters the following objective function was used:

$$
\mathrm{RMSD}=\sum_{i} \sum_{j}\left[\frac{\left(x_{i}^{\text {exp }}-x_{i}^{\text {calc. }}\right)^{2}}{6 M}\right]^{0.5},
$$

where " $x_{i}$ " is mass fraction of each phase in product.

This model used an optimization algorithm using NelderSimplex method and a root mean square deviation (RMSD) function. " $M$ " is the number of tie lines in the experiment.

In order to examine the other thermodynamic properties, it was needed to calculate an important thermodynamic energy function. Based on thermodynamic of mixture and equilibrium definition, a reaction can be defined as a spontaneous reaction, when its Gibbs energy changing through a process is negative. A reaction is more spontaneous when it reaches a more negative Gibbs energy value. In order to examine this fact, excess Gibbs energy values for four reactions were calculated. Gibbs free energy correlation for NRTL model is shown in.

$$
\frac{G^{E}}{R T}=\sum_{i=1}^{m} x_{i} \frac{\sum_{j=1}^{m} \tau_{j i} G_{j i} x_{j}}{\sum_{l=1}^{m} G_{l i} x_{l}} .
$$

$G_{i j}$ and $\tau_{i j}$ are shown in (2) and (3), respectively.

\section{Results and Discussion}

3.1. Effect of Temperature Increasing Rate. The results of pyrolysis experiments are shown in Table 3.

As shown in Table 3, LDPE and PP produced maximum liquid product, this is because of the different reaction mechanism of these two polymers with another plastic compound (PET). As mentioned in Table 1, LDPE and PP are degraded based on random chain rapture, and it was expectable. But, the degradation mechanism of PET is converting to the other chemical structures with less energy content. This mechanism leads to produce compound with higher thermal stability and boiling point. Then, PET produces more char products towards two other polymeric compounds [1, page 12].

Based on Table 3 it is obvious that the lower temperature increasing rate leads to higher liquid product content. By increasing the temperature increasing rate, liquid product was decreased. This could be shown in Figure 2.

Figures 2 to 4 show a comparison between solid, liquid, and gas products of the three used polymers. As shown in Figure 2 the liquid product of each polymer was decreased by increasing the temperature increasing rate. It is because of the second set of reactions (converting tar to char and gas product) that occurred in the reactor. When we applied a higher temperature, the reaction products were faced with a higher temperature before leaving the reactor. Thus, another series of cracking reactions were done on the products; that could be shown in Figure 5 [11].

Based on Figure 5, the liquid product converts to solid and gas products at a higher temperature. In order to
TABLE 3: Results of pyrolysis reaction at different temperature increasing rates and raw materials.

\begin{tabular}{lcccc}
\hline $\begin{array}{l}\text { Plastic } \\
\text { waste }\end{array}$ & $\begin{array}{c}\text { Temperature } \\
\text { increasing } \\
\text { rate }\left({ }^{\circ} \mathrm{C} / \mathrm{min}\right)\end{array}$ & $\begin{array}{c}\text { Solid product } \\
\text { (weight \%) }\end{array}$ & $\begin{array}{c}\text { Liquid } \\
\text { product } \\
\text { (weight \%) }\end{array}$ & $\begin{array}{c}\text { Gas product } \\
\text { (weight \%) }\end{array}$ \\
\hline LDPE & 6 & 0.16 & 80.41 & 19.43 \\
LDPE & 8 & 0.11 & 79.64 & 20.23 \\
LDPE & 10 & 0.09 & 76.45 & 23.46 \\
LDPE & 12 & 0.04 & 74.32 & 25.64 \\
LDPE & 14 & 0.04 & 71.11 & 28.85 \\
PET & 6 & 8.98 & 38.89 & 52.13 \\
PET & 8 & 8.12 & 34.16 & 57.72 \\
PET & 10 & 7.64 & 32.13 & 60.23 \\
PET & 12 & 6.61 & 30.33 & 63.03 \\
PET & 14 & 5.74 & 29.14 & 65.12 \\
PP & 6 & 0.12 & 82.12 & 17.76 \\
PP & 8 & 0.09 & 81.32 & 18.68 \\
PP & 10 & 0.07 & 80.65 & 19.28 \\
PP & 12 & 0.04 & 79.41 & 20.55 \\
PP & 14 & 0.0 & 78.26 & 21.74 \\
\hline
\end{tabular}

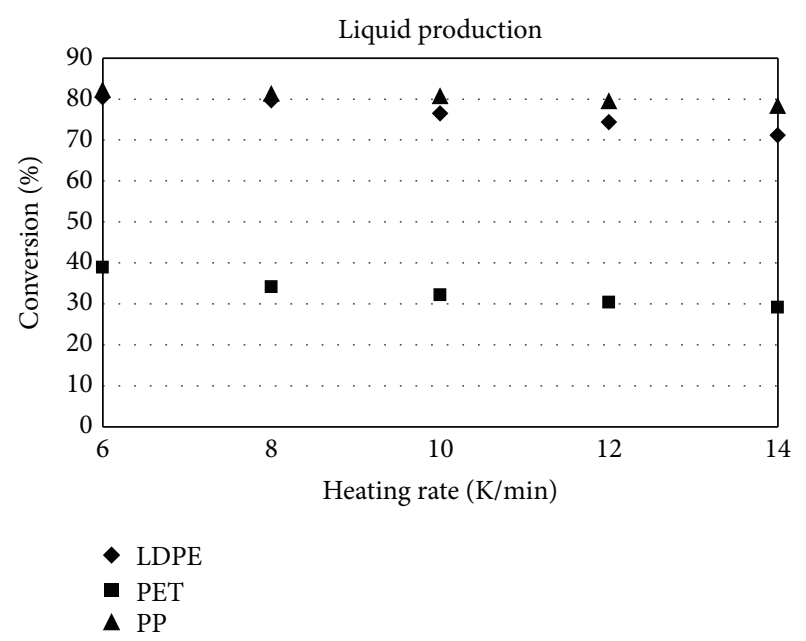

FIGURE 2: The effect of temperature increasing rate on liquid product of each plastic compound.

prevent these reactions, we have to maintain the reaction temperature in the lowest possible temperature and with lower temperature increasing rate.

Therefore, solid and gas products of each reaction were higher at higher temperature increasing rates that are shown in Figures 3 and 4.

3.2. NRTL Activity Coefficient Model. The activity coefficient model that was used for this reaction gave a good result in computing RMSD objective function. Using NRTL model, the following binary interaction parameters were obtained (Table 4). 


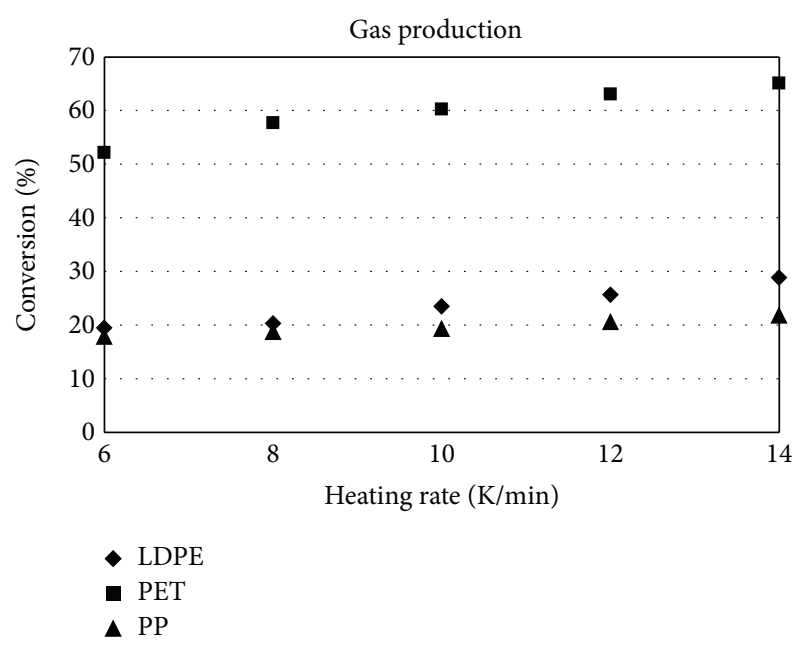

FIGURE 3: The effect of temperature increasing rate on gas product of each plastic compound.

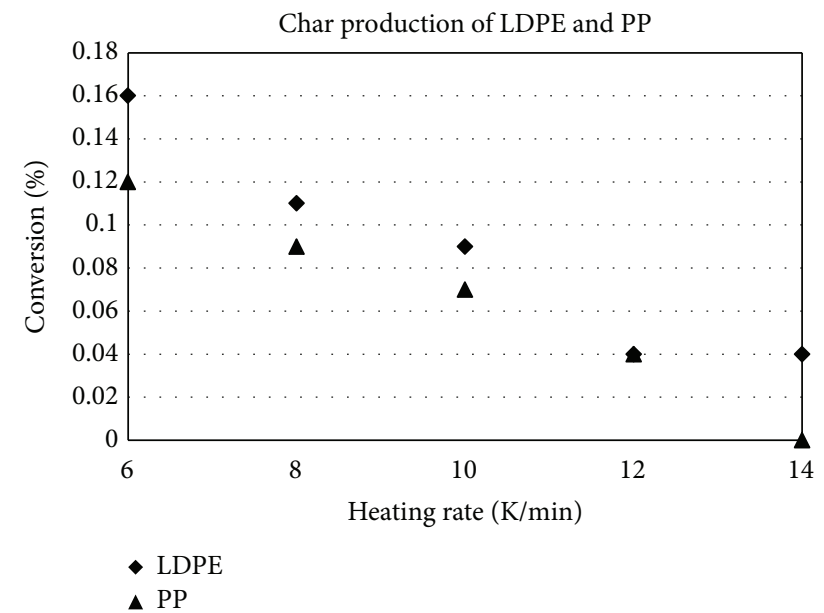

FIGURE 4: The effect of temperature increasing rate on solid product of each plastic compound.

Using these parameters, the RMSD was calculated with a low value equal to 0.0157 . This RMSD is acceptable for the model.

The results of Gibbs free energy are shown in Figure 6. As it is shown in Figure 6, more reduction in Gibbs free energy is seen at higher temperature raising ratios. This more reduction means more deviation from equilibrium state (changing more rapidly in temperature and being far from temperature equilibrium state).

The other important thermodynamic function is activity coefficient $(\gamma)$. Activity coefficient could be calculated after adjusting the binary interaction parameters.

Activity coefficient values at various experimental conditions for three products are plotted in Figures 7, 8, and 9.

As it is shown in Figures 7 to 9, the activity coefficients of char phase present a different behavior via temperature raising ratio. The activity coefficients of char are increasing function but the activity coefficients of oil and gas phase are decreasing function. This difference can be described based

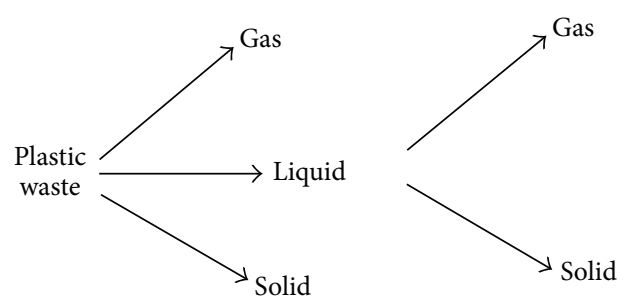

FIGURE 5: The second set of reactions that convert the liquid product to solid and gas.

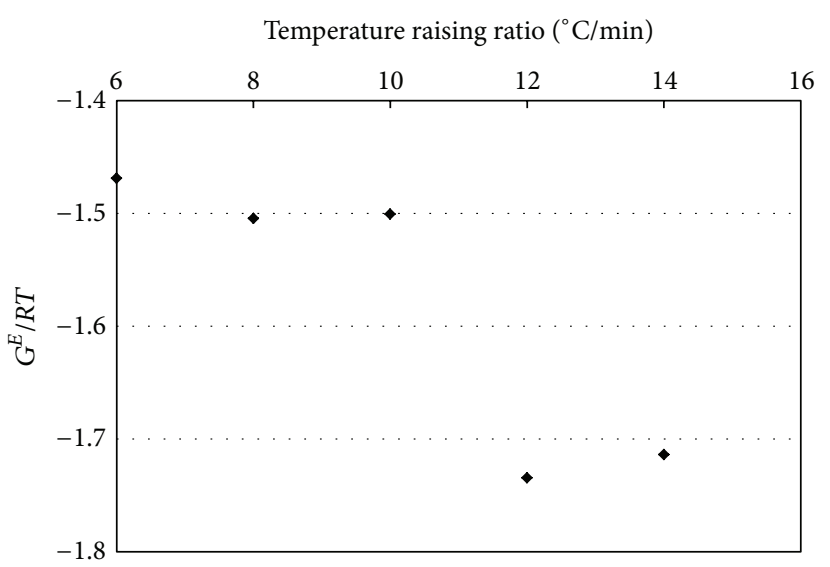

FIgURE 6: Excess Gibbs energy at different temperature raising ratios.

TABLE 4: Calculated binary interaction parameters for minimizing the RMSD objective function.

\begin{tabular}{lccc}
\hline $\begin{array}{l}\text { Binary interaction } \\
\text { coefficient }\end{array}$ & $\begin{array}{c}\text { Char }(i) \\
\text { Oil }(j)\end{array}$ & $\begin{array}{c}\text { Char }(i) \\
\text { Gas }(j)\end{array}$ & $\begin{array}{c}\text { Oil }(i) \\
\text { Gas }(j)\end{array}$ \\
\hline$a_{i j}$ & 1.5324 & 3.9759 & -7.3278 \\
$a_{j i}$ & 1.1193 & 2.5111 & 1.6085 \\
$b_{i j}$ & 1.0865 & -0.3565 & 3.9257 \\
$b_{j i}$ & 2.1687 & 6.2060 & 0.7008 \\
\hline
\end{tabular}

on Figure 5. The higher temperature raising ratio leads to converting more oil product to char and gas. Then, the activity coefficient of char is increased after increasing the ratio.

\section{Conclusion}

Results show that polypropylene produced maximum liquid product that was $82 \%$ at lowest temperature increasing rate $\left(6^{\circ} \mathrm{C} / \mathrm{min}\right)$. All results confirm that the lower temperature increasing rate leads to higher liquid product.

NRTL activity coefficient model could predict the reaction products very carefully. The RMSD objective function converged with new binary interaction parameters in 0.0157; that is a reliable value for RMSD value. Using NRTL activity coefficient model can be verified by computing excess Gibbs values and activity coefficients. The computed values verified the basic concepts about spontaneous reactions. 


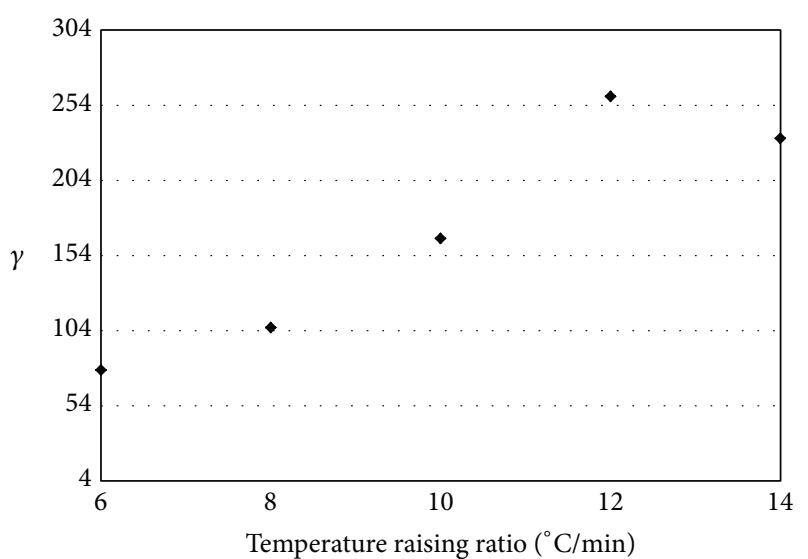

FIGURE 7: Activity coefficient of produced char at different temperature raising ratios.

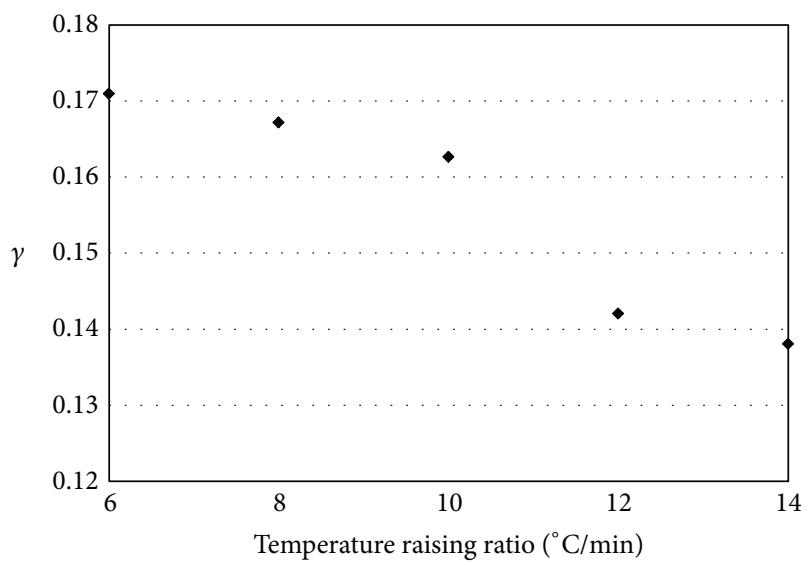

Figure 8: Activity coefficient of produced oil phase at different temperature raising ratios.

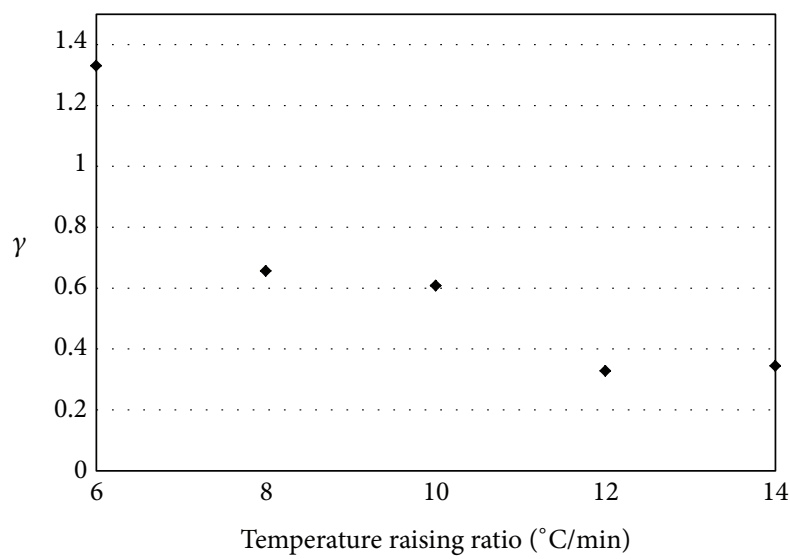

Figure 9: Activity coefficient of produced gas phase at different temperature raising ratios.

\section{Acknowledgment}

This project was done by financial support of the Islamic Azad University, Omidiyeh branch, as a research project, and the author appreciates the financial and experimental support.

\section{References}

[1] J. Scheirs and W. Kaminsky, Feedstock Recycling and Pyrolysis of Waste Plastic: Converting Waste Plastics into Diesel and Other Fuels, Wiley Series in Polymer Science, 2006.

[2] W. J. Hall and P. T. Williams, "Analysis of products from the pyrolysis of plastics recovered from the commercial scale recycling of waste electrical and electronic equipment," Journal of Analytical and Applied Pyrolysis, vol. 79, no. 1-2, pp. 375-386, 2007.

[3] W. Kaminsky and J.-S. Kim, "Pyrolysis of mixed plastics into aromatics," Journal of Analytical and Applied Pyrolysis, vol. 51, no. 1, pp. 127-134, 1999.

[4] A. López, I. de Marco, B. M. Caballero, M. F. Laresgoiti, and A. Adrados, "Pyrolysis of municipal plastic wastes: influence of raw material composition," Waste Management, vol. 30, no. 4, pp. 620-627, 2010.

[5] P. T. Williams and E. Slaney, "Analysis of products from the pyrolysis and liquefaction of single plastics and waste plastic mixtures," Resources, Conservation and Recycling, vol. 51, no. 4, pp. 754-769, 2007.

[6] S. Jung, M. Cho, B. Kang, and J. Kim, "Pyrolysis of a fraction of waste polypropylene and polyethylene for the recovery of BTX aromatics using a fluidized bed reactor," Fuel Processing Technology, vol. 91, pp. 277-284, 2010.

[7] G. Jie, L. Ying-Shun, and L. Mai-Xi, "Product characterization of waste printed circuit board by pyrolysis," Journal of Analytical and Applied Pyrolysis, vol. 83, no. 2, pp. 185-189, 2008.

[8] L. Vivero, C. Barriocanal, R. Álvarez, and M. A. Díez, "Effects of plastic wastes on coal pyrolysis behaviour and the structure of semicokes," Journal of Analytical and Applied Pyrolysis, vol. 74, no. 1-2, pp. 327-336, 2005.

[9] N. Miskolczi, A. Angyal, L. Bartha, and I. Valkai, "Fuels by pyrolysis of waste plastics from agricultural and packaging sectors in a pilot scale reactor," Fuel Processing Technology, vol. 90, pp. 1032-1040, 2009.

[10] H. Renon and J. M. Prausnitz, "Estimation of parameters for the NRTL equation for excess gibbs energies of strongly nonideal liquid mixtures,' I and EC Process Design and Development, vol. 8, no. 3, pp. 413-419, 1969.

[11] Y. B. Yang, A. N. Phan, C. Ryu, V. Sharifi, and J. Swithenbank, "Mathematical modelling of slow pyrolysis of segregated solid wastes in a packed-bed pyrolyser," Fuel, vol. 86, no. 1-2, pp. 169$180,2007$. 

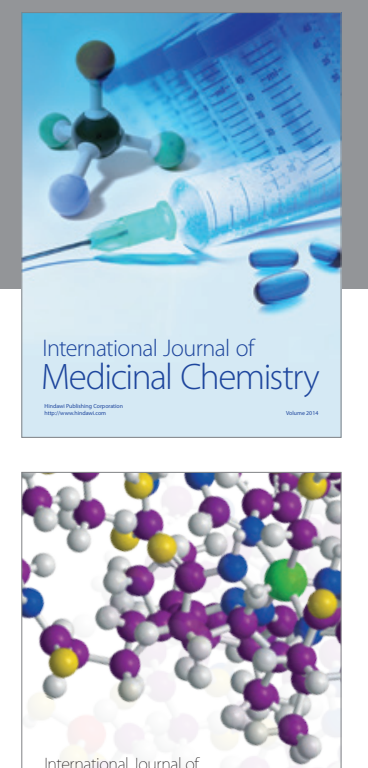

\section{Carbohydrate} Chemistry

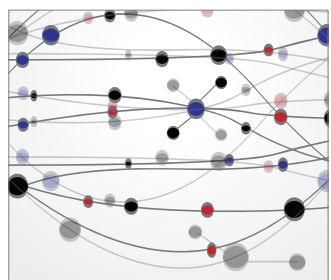

The Scientific World Journal
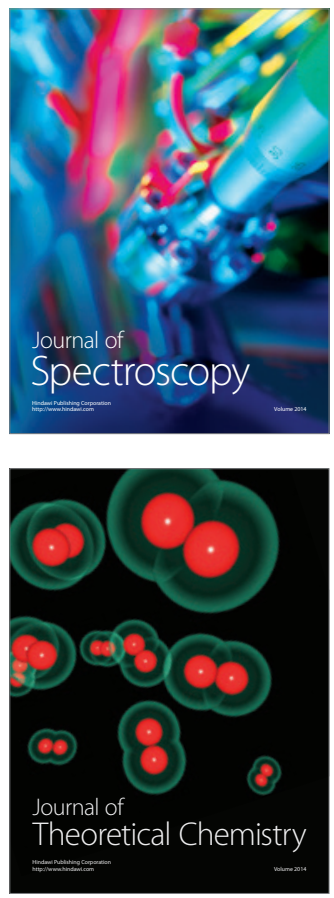
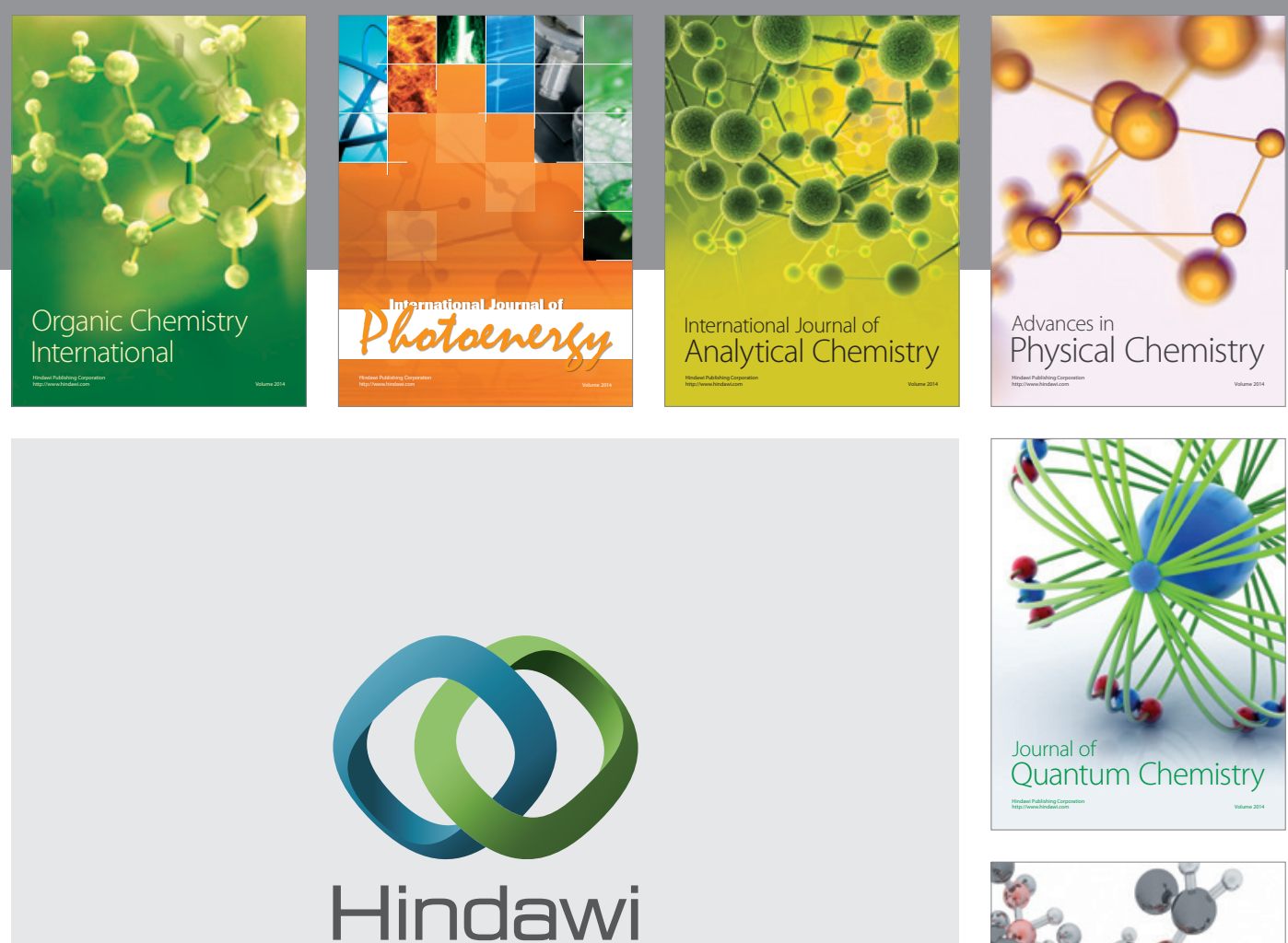

Submit your manuscripts at

http://www.hindawi.com

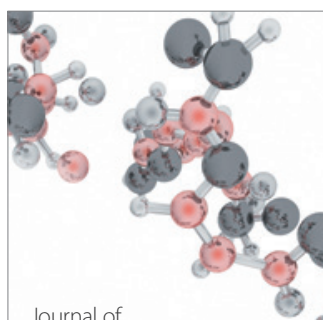

Analytical Methods

in Chemistry

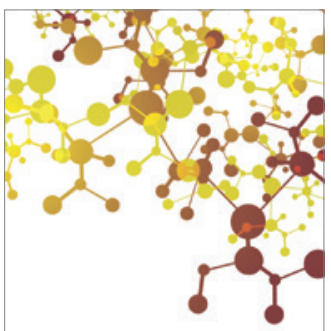

Journal of

Applied Chemistry

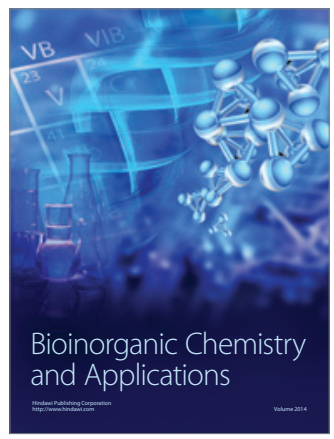

Inorganic Chemistry
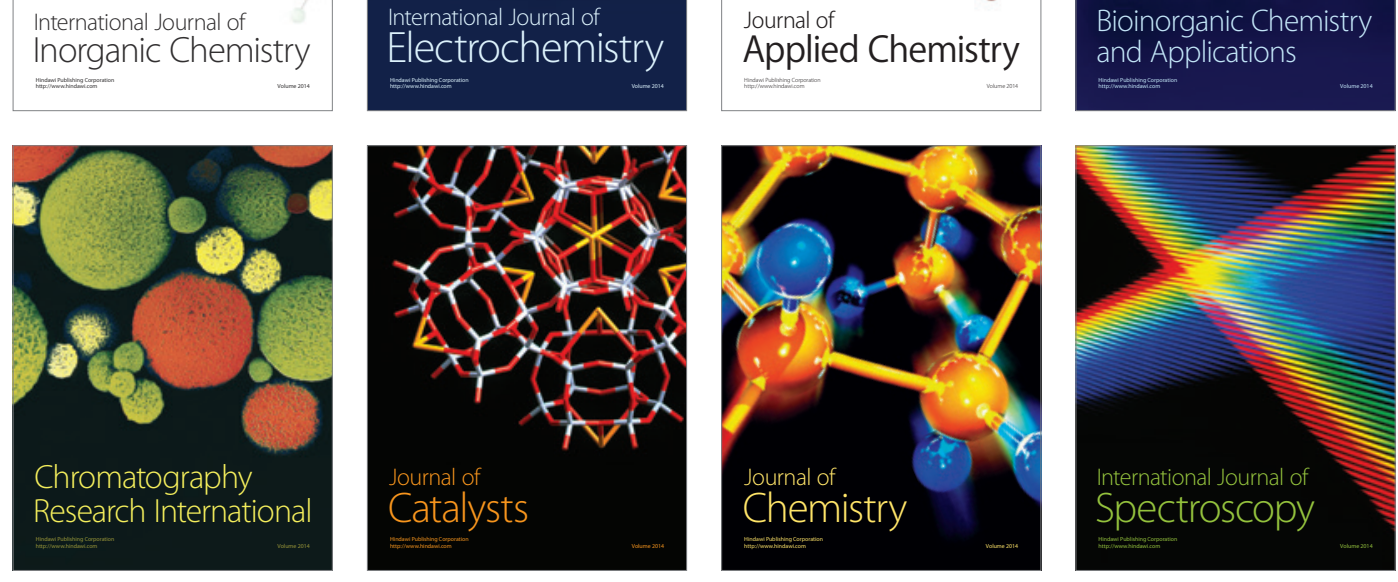